\title{
RESPONSABILIDADE CIVIL DA UNIÃO FEDERAL PELA POLITIZAÇÃO DA UTILIZAÇÃO OFF LABEL DA CLOROQUINA NO TRATAMENTO DA COVID-19
}

\author{
CIVIL LIABILITY OF THE FEDERAL UNION FOR \\ POLITIZING THE OFF-LABEL USE OF CHLOROQUINE \\ IN THE TREATMENT OF COVID-19
}

\begin{abstract}
Joyceane Bezerra de Menezes
Pós-Doutorado em "Novas Tecnologias e Direito" na Mediterranea Internacional Centre for Human Rights Research (MICHR), Departamento de Direito, Economia e Humanidades - Universidade Reggio Calabria (Itália). Doutora em Direito pela Universidade Federal de Pernambuco. Mestre em DireitoConstitucional pela Universidade Federal do Ceará. Graduada em Direito pela Universidade de Fortaleza. Pós-Doutora em Direito Civil pela Universidade do Estado do Rio de Janeiro. Professora titular da Universidade de Fortaleza, integrando o Programa de Pós-Graduação Stricto Sensu em Direito. Professora associada da Universidade Federaldo Ceará - Faculdade de Direito (Departamento de Direito Privado). Advogada em Fortaleza - Ceará. ORCID: https://orcid.org/0000-0002-5710-9977
\end{abstract}

\section{Patrícia K. de Deus Círiaco}

Doutoranda pelo Programa de Pós-Graduação Stricto Sensu em Direito (PPGD) da Universidade de Fortaleza, Ceará. Mestre em Ciências Jurídico-Políticas (Menção em Direito Constitucional) pela Universidade de Coimbra, Portugal. Professora. Advogada em Fortaleza - Ceará. ORCID: http://orcid.org/0000-0002-2739-9213

\begin{abstract}
Resumo: Diante dos desafios enfrentados pela pandemia ocasionada pela Covid-19, o Brasil tem se destacado pela utilização off label da cloroquina (e da hidroxicloroquina), apesar das muitas controvérsias na literatura médico-científica nacional e internacional. Contudo, para além da utilização do fármaco no âmbito médico privado, a adoção desse medicamento ganhou conotação política, a partir dos reiterados discursos do presidente da República que findaram por reformar o protocolo do SUS no tratamento da doença em oposição ao estado da arte das ciências médico-farmacológicas. Considerando o discurso presidencial e as orientações do Ministério da Saúde por meio do protocolo geral que vincula o SUS ao uso desse medicamento no tratamento da Covid-19, examinam-se as possibilidades de responsabilização civil da União pelos eventuais efeitos adversos materializados em danos ao paciente.
\end{abstract}

Palavras-chave: Responsabilidade civil da União Federal. Dano. Cloroquina/hidroxicloroquina. Uso off label. Covid-19.

Abstract: With the challenges faced by the pandemic caused by Covid-19, Brazil has stood out for the off-line use of chloroquine (and hydroxychloroquine), despite the many controversies in the national and international medical-scientific literature. However, in addition to the use of the drug in the private 
medical field, the adoption of this medicine gained political connotation, based on the repeated speeches of the President of the Republic that ended up reforming the S.U.S protocol in the treatment of the disease in opposition to the state of the art of science medical-pharmacological. Considering the presidential speech and the guidelines of the Ministry of Health through the general protocol that links the S.U.S to the use of this medicine in the treatment of Covid-19, the possibilities of civil liability of the Union for possible adverse effects materialized in damages to the patient are examined.

Keywords: Federal Union civil liability. Damage. Chloroquine/hydroxychloroquine. Use off label. Covid-19.

Sumário: 1 Introdução - 2 A utilização off label da cloroquina para o tratamento da Covid-19 - 3 A politização do uso off label da cloroquina e o ensejo ao vício de consentimento informado - 4 Responsabilidade civil da União Federal pela politização da utilização off labe/ da cloroquina para o tratamento da Covid-19 - 5 Conclusão

\section{Introdução}

Declarada a pandemia causada pela Covid-19 como emergência de saúde pública de importância internacional (ESPII), o mais alto grau de alerta, pela Organização Mundial da Saúde, ${ }^{1}$ os cientistas de diversos países intensificaram suas pesquisas em busca do tratamento adequado e da criação de vacina para a cura e imunização da população. Contudo, enquanto se buscam respostas mais definitivas, a utilização off label de alguns medicamentos passou a ser uma das únicas alternativas de enfrentamento aos sintomas causados pelo vírus.

No Brasil, ganharam relevo e espaço na pauta de discussões populares e midiáticas a cloroquina e a hidroxicloroquina, instaurando-se um debate polarizado sobre a sua conveniência e adequação ao tratamento da Covid-19. A discussão ultrapassou o ambiente médico científico, reverberando no cenário político, a partir das reiteradas declarações do presidente da República que, por sua vez, ecoava a voz do Presidente norte-americano Donald Trump.

Sabe-se, contudo, que a utilização off label da cloroquina (e da hidroxicloroquina) para o tratamento do coronavírus é bastante controversa entre os cientistas, haja vista as diversas publicações nacionais e internacionais, cujas conclusões apontam a ineficácia e não recomendação do seu uso. Os efeitos colaterais são severos o suficiente para desequilibrar o binômio risco-benefício, quando aplicado ao fim de combater a doença em questão.

A própria Organização Mundial de Saúde (OMS), entre idas e vindas, chegou a anunciar a interrupção e retomada de testes com o medicamento. Em sua última

\footnotetext{
ORGANIZAÇÃO MUNDIAL DE SAÚDE (OMS). Declaração do diretor-geral sobre a reunião do Comitê de Emergência do Regulamento Sanitário Internacional (2005) sobre o novo coronavírus (2019 n-CoV). 30 jan. 2020. Disponivel: https://www.who.int/dg/speeches/detail/who-director-general-s-statement-on-ihr-emergencycommittee-on-novel-coronavirus-(2019-ncov). Acesso em: 27 maio 2020.
} 
manifestação sobre o tema, datada de 17.6.2020, afirmou a suspensão desses testes pelo Grupo de Pesquisa Internacional Solidariedade.

A Sociedade Brasileira de Imunologia emitiu parecer desaconselhando o uso do medicamento e, no mesmo sentido, foram as diretrizes publicadas pela Associação de Medicina Intensiva Brasileira, Sociedade Brasileira de Infectologia e Sociedade Brasileira de Pneumologia e Tisiologia. Semelhantemente, foi a moção da Faculdade de Ciências Farmacêuticas da Universidade de São Paulo, desaconselhando o uso da cloroquina no tratamento da doença gerada pelo coronavírus.

Recentemente, em 25.6.2020, o Hospital Albert Einstein manifestou-se publicamente pela não recomendação dos medicamentos. $E$ assim o fez, seguindo a determinação da Administração de Alimentos e Drogas dos Estados Unidos (FDA), que revogou a autorização de utilização emergencial da cloroquina para tratamento da Covid-19.

Na contramão das conclusões científicas e dos órgãos técnicos acima anunciados exemplificativamente, o Governo Federal brasileiro incluiu o fármaco nas políticas públicas de combate à Covid-19, que, a partir das recomendações do Ministério da Saúde, passou a compor o protocolo de caráter geral e vinculativo do Sistema Único de Saúde (SUS). Prescreve-se a cloroquina (e a hidroxicloroquina), inclusive, para o tratamento preventivo da doença, bastando que exista uma orientação médica e a assinatura do paciente em um termo-padrão de consentimento fornecido pelo Governo Federal.

Apesar de todas as adversidades associadas à Covid-19, o enfrentamento da pandemia no Brasil vem sendo tratado, por parte do Governo Federal, em especial pelo presidente da República, como uma guerra política que agudiza a polaridade entre direita e esquerda desde o período eleitoral de 2018. A divisão da população é tão demarcada que o próprio presidente da República, em tom jocoso, afirmou: "quem é de direita usa cloroquina; quem não é, usa tubaína".

Ante a essas considerações, o objeto do artigo é o de analisar a responsabilidade civil da União pelo dano associado aos efeitos adversos da cloroquina e/ou hidroxicloroquina prescritas em atenção às orientações do Ministério da Saúde, cujo protocolo geral é vinculado ao SUS, no contexto político e social em que o discurso do presidente da República reafirma a eficiência do medicamento. Entende-se que a postura presidencial pode induzir ou influenciar o cidadão, contribuindo para o consentimento viciado quanto ao uso do remédio.

Como proposta de desenvolvimento, inicia-se o estudo pela análise da utilização off label da cloroquina e suas controvérsias no campo médico científico para o tratamento da Covid-19. Em seguida, aponta-se o problema da politização da utilização off label da cloroquina, adotada como política pública pelo Governo Federal para o tratamento do coronavírus, além do discurso político do presidente 
da República como ensejador do vício de consentimento. Por fim, abordam-se os aspectos da teoria do risco administrativo para justificar a responsabilidade civil do Estado diante da situação apresentada.

Para tal, foi realizada pesquisa documental e bibliográfica na doutrina nacional e comparada, bem como pesquisa na legislação e jurisprudência nacional, sendo esses dados analisados por meio dos métodos dedutivo e indutivo respectivamente.

\section{A utilização off label da cloroquina para o tratamento da Covid-19}

No Brasil, cabe à Agência Nacional de Vigilância Sanitária registrar o medicamento, depois de cumpridos os requisitos de segurança exigidos. Nesse registro constam as indicações aprovadas para o uso do fármaco (uso on label). Quando utilizado para além dessas indicações não especificadas, tem-se o uso off label. É possível que um fármaco seja autorizado para uma ou mais indicações e, adiante, após novos estudos e estágios clínicos necessários, também vir a ser recomendado para outras.

Para tanto, é preciso submeter a ampliação do uso à agência competente que prevê todos os processos dessa submissão e análise. ${ }^{2}$ Por meio da Resolução da Diretoria Colegiada - RDC no 9, a Anvisa estabelece os ensaios clínicos necessários para autorização de novas indicações aos medicamentos já registrados, exigindo o cumprimento de três fases de ensaios clínicos. ${ }^{3}$

Para Meadows e Hollowell, o uso off label implica silent label, porque traz a prescrição de um fármaco não registado, ainda em fase de testes; ou daquele já registrado, mas sem indicação específica para o tratamento de determinada enfermidade na bula correspondente. ${ }^{4}$

${ }^{2}$ BRASIL. Agência Nacional de Vigilância Sanitária (Anvisa). Uso off label de medicamento. Disponível em: http://portal.anvisa.gov.br/resultado-de-busca?p_p_id=101\&p_p_lifecycle=0\&p_p_state=maximized\&p_p_ mode=view\&p_p_col_id=column-1\&p_p_col_count=1\&_101_struts_action=\%2Fasset_publisher\%2Fview_ content\&_101_assetEntryld=352702\&_101_type=content\&_101_groupld=33836\&_101_urlTitle=como- aanvisa-ve-o-uso-off-label-de-medicamentos\#: : :text=0\%20uso\%20off\%20label\%20de\%20um\%20 medicamento\%20\%C3\%A9\%20feito\%20por,correto\%2C\%20apenas \%20ainda\%20n\%C3\%A3o\%20 aprovado\%3E. Acesso em: 3 jun. 2020.

${ }^{3}$ BRASIL. Agência Nacional de Vigilância Sanitária (Anvisa). Resolução de Diretoria Colegiada - RDC 09 de 20 de fevereiro de 2015. Diário Oficial da União, Brasília, n. 41, 3 mar. 2015. Disponível em: http:// portal.anvisa.gov.br/documents/10181/3503972/RDC_09_2015_.pdf/843a88bd-3381-489e-8711aca256cb4360. Acesso em: 3 jun. 2020.

4 "Therefore, '[o]ff-label thus only means 'silent' label.' 'The term denotes nothing about health risks or benefits, and therefore means nothing in the medical context of informed consent"' (MEADOWS, W. A.; HOLLOWELL, B. D. 'Off-label' drug use: an FDA regulatory term, not a negative implication of its medical use. 
Por razões de segurança, a formalização registral de um medicamento com as respectivas indicações é que garante a sua utilização on label. Ministrar uma medicação fora desses termos é assumir o risco de sua utilização não registrada e chancelada pela agência competente que, no Brasil, é a Agência Nacional de Vigilância Sanitária (Anvisa). Portanto, o uso off labelé desaconselhado e aquele que assim o prescreve pode ser chamado à responsabilidade civil e deontológica.

Segundo Carvalho, ${ }^{5}$ a prática de indicação de medicamentos sem evidências clínicas e para hipóteses diversas daquelas estudadas e preconizadas (uso off label) deve ser desencorajada, porque está comprovadamente associada à ampliação dos efeitos adversos. Se o médico realizar os atos necessários de diligência e informação ao paciente, ${ }^{6}$ a prescrição off labe/ não é ilícita. Mas isso não exime os riscos de danos, pois sem os ensaios clínicos prévios não há como saber se o medicamento em uso trará benefício real ou maior prejuízo. ${ }^{7}$

Porém, no cenário de perplexidade instaurado, a comunidade médica se viu impingida a testar diversos medicamentos, recorrendo ao uso off label, na tentativa de controlar os múltiplos sintomas da doença. Seguindo a própria experiência profissional, a orientação de alguns estudos científicos aos quais se filiam e a prática dos países que antecederam o Brasil no enfrentamento pandêmico, usaram diversos fármacos, incluindo-se a cloroquina e/ou hidroxicloroquina.

É certo, como dizem Meadows e Hollowell, que a ciência e a medicina se movimentam mais rapidamente que a burocracia estatal no processo de regularização de um medicamento. Embora conheçam as propriedades de certas drogas, o lançamento para uso é contido pela necessidade de cumprimento das exigências legais de cada país. Assim, considerando a existência das doenças órfãs (orphan diseases), para as quais não há o interesse da indústria farmacêutica em investir

International Journal of Impotence Research, London, v. 20, n. 2, p. 135-144, 2018. p. 140. Disponível em: https://www. nature.com/articles/3901619.pdf. Acesso em: 2 jul. 2020).

5 CARVALHO, Marisa Lima. O desafio do uso off label de medicamentos. Rev. paul. pediatr., São Paulo, v. 34, n. 1, p. 1-2, mar. 2016. Disponível em: https://www.scielo.br/scielo.php?pid=S0103-0582201600010 $0001 \&$ script=sci_arttext\&tlng=pt. Acesso em: 3 jul. 2020.

${ }^{6}$ Nesse sentido: "A licitude da prescrição off label de medicamento, mesmo que fundada em pesquisa pouco conhecida, dependerá de seu embasamento, sendo provável a utilidade de sistema de evidências. O uso inovador, meramente experimental e sem base em evidência pode permanecer fora do campo do que se pode chamar de exercício regular do direito de prescrever, especialmente se inobservados os deveres anexos à relação médico-paciente (sobretudo quanto ao dever de informação qualificada)" (NOGUEIRA, Roberto Henrique Pôrto. Responsabilidade civil do médico na prescrição off label de medicamentos para a Covid-19. In: MONTEIRO FILHO, Carlos Edison do Rêgo; ROSENVALD, Nelson; DENSA, Roberta (Org.). Coronavírus e responsabilidade civil: impactos contratuais e extracontratuais. Indaiatuba: Foco, 2020. p. 290).

7 CONSELHO FEDERAL DE MEDICINA. Parecer CFM $n^{\circ}$ 4/2020. Considera o uso da cloroquina e hidroxicloroquina, em condições excepcionais, para o tratamento da Covid-19. 16 abr. 2020. p. 5. Disponível em: https://sistemas.cfm.org.br/normas/visualizar/pareceres/BR/2020/4. Acesso em: 14 jun. 2020. 
no processo de aprovação e fabricação de medicamentos específicos, e o surgimento de novas doenças, a prescrição off labe/ pode ser uma solução admissível ou mesmo uma necessidade. ${ }^{8}$

No Brasil, especialmente depois da expressa recomendação do Ministério da Saúde, a prescrição off label da cloroquina (e da hidroxicloroquina) para o tratamento dessa doença é muito recorrente. Mas as indicações constantes no registro junto à Anvisa são apenas para doenças como lúpus, artrite reumatoide ou malária. Sem estudos clínicos robustos, o uso do fármaco em pacientes com o coronavírus pode ser mais maléfico que benéfico. Enquanto é imprecisa a sua eficiência para o doente da Covid-19, o medicamento apresenta um potencial lesivo severo à vista dos efeitos adversos, que podem ir de mera irritação no trato gastrointestinal à forma mais grave derivativa de sua toxicidade ocular, cardíaca, neurológica e cutânea. $^{9}$

O Conselho Federal de Medicina manifestou-se sobre a temática por meio do Parecer no 4/2020, reiterando que não há, até o momento, uma terapia farmacológica específica para o tratamento do coronavírus e que, embora haja dezenas de medicamentos em teste desde o final de 2019, "nenhum ainda foi aprovado em ensaios clínicos com desenho cientificamente adequado, não podendo, portanto, serem recomendados com segurança". ${ }^{10}$ A partir da ementa, o parecer dispôs: "Considera o uso da cloroquina e hodroxicloroquina, em condições excepcionais, para o tratamento da COVID-19". Alerta para todos os riscos associados ao medicamento e a inexistência de comprovação de sua eficácia diante da Covid-19. Mesmo assim, libera da responsabilidade ética o médico que vier a prescrever o uso off label da cloroquina para tratar os sintomas da Covid-19, ${ }^{11}$ quando houver o consentimento informado do paciente. ${ }^{12}$

\footnotetext{
${ }^{8}$ MEADOWS, W. A.; HOLLOWELL, B. D. 'Off-label' drug use: an FDA regulatory term, not a negative implicationof its medical use. International Journal of Impotence Research, London, v. 20, n. 2, p. 135-144, 2018. p. 139. Disponível em: https://www.nature.com/articles/3901619.pdf. Acesso em: 2 jul. 2020

${ }^{9}$ CONSELHO FEDERAL DE MEDICINA. Parecer CFM $n^{\circ}$ 4/2020. Considera o uso da cloroquina e hidroxicloroquina, em condições excepcionais, para o tratamento da Covid-19. 16 abr. 2020. p. 5-6. Disponível em: https://sistemas.cfm.org.br/normas/visualizar/pareceres/BR/2020/4. Acesso em: 14 jun. 2020.

${ }^{10}$ CONSELHO FEDERAL DE MEDICINA. Parecer CFM nำ 4/2020. Considera o uso da cloroquina e hidroxicloroquina, em condições excepcionais, para o tratamento da Covid-19. 16 abr. 2020. p. 4. Disponível em: https://sistemas.cfm.org.br/normas/visualizar/pareceres/BR/2020/4. Acesso em: 14 jun. 2020.

${ }^{11}$ Destaca-se o item "e" do Parecer no 4/2020, que assegura aos médicos, diante da excepcionalidade da situação pandêmica, não qualificar a prescrição e administração da cloroquina/hidroxicloroquina como uma infração ética. Franqueia a decisão à autonomia do médico e do paciente (CONSELHO FEDERAL DE MEDICINA. Parecer CFM nํ 4/2020. Considera o uso da cloroquina e hidroxicloroquina, em condições excepcionais, para o tratamento da Covid-19. 16 abr. 2020. p. 7. Disponível em: https://sistemas.cfm. org.br/normas/visualizar/pareceres/BR/2020/4. Acesso em: 14 jun. 2020).

${ }^{12}$ CONSELHO FEDERAL DE MEDICINA. Parecer CFM $n^{\circ}$ 4/2020. Considera o uso da cloroquina e hidroxicloroquina, em condições excepcionais, para o tratamento da Covid-19. 16 abr. 2020. p. 6-7. Disponível em: https://sistemas.cfm.org.br/normas/visualizar/pareceres/BR/2020/4. Acesso em: 14 jun. 2020.
} 
A comunidade médico-científica, como já referido, divide-se quanto à utilização off label (ou não) do medicamento. A Sociedade Americana de Doenças Infecciosas, em documento datado de 11.4.2020, recomendou a utilização da cloroquina e da hidroxicloroquina, com a ressalva de que sejam utilizadas apenas em pacientes internados sob protocolos clínicos de pesquisa. ${ }^{13}$

Já a Sociedade Brasileira de Imunologia (SBI) emitiu, em 10.5.2020, um parecer assinado pelos 17 integrantes do comitê científico e pelos cinco membros de sua diretoria, desaconselhando a sua utilização para a Covid-19, sob o fundamento de que o fármaco só apresenta eficácia terapêutica em face de enfermidades como malária e doenças reumáticas. O parecer chama atenção para o fato de que, além da ineficácia para tratar a Covid-19, a sua utilização poderá precipitar o óbito do paciente em razão dos seus efeitos adversos. ${ }^{14}$

Rosenberg et al. consolidaram um estudo bem abrangente, observando um total de 1.438 pacientes com o vírus, internados em 25 hospitais diferentes, e concluíram que aqueles que foram tratados com hidroxicloroquina e azitromicina sofreram maior incidência de falência cardíaca do que o grupo que não utilizou o fármaco no seu tratamento. ${ }^{15}$

Em 19.5.2020, foi publicado no Brasil um outro documento, intitulado Diretrizes para o tratamento farmacológico da Covid-19 - elaborado a partir do consenso entre a Associação de Medicina Intensiva Brasileira, a Sociedade Brasileira de Infectologia e a Sociedade Brasileira de Pneumologia e Tisiologia, desaconselhando a utilização off labe/ da cloroquina. $O$ documento apresentou onze recomendações e ressaltou, nas duas primeiras, a não utilização da cloroquina ou hidroxicloroquina e a sua não combinação com a azitromicina na rotina do tratamento da Covid-19. ${ }^{16}$

${ }^{13}$ CONSELHO FEDERAL DE MEDICINA. Parecer CFM $n^{\circ}$ 4/2020. Considera o uso da cloroquina e hidroxicloroquina, em condições excepcionais, para o tratamento da Covid-19. 16 abr. 2020. p. 3. Disponível em: https://sistemas.cfm.org.br/normas/visualizar/pareceres/BR/2020/4. Acesso em: 14 jun. 2020.

${ }^{14}$ SOCIEDADE BRASILEIRA DE IMUNOLOGIA (SBI). Parecer científico da Sociedade Brasileira de Imunologia (SBI) sobre a utilização da cloroquina/hidroxicloroquina para o tratamento da Covid-19. 10 maio 2020. Disponível em: https://sbi.org.br/2020/05/18/parecer-da-sociedade-brasileira-de-imunologia-sobre-autilizacao-da-cloroquina-hidroxicloroquina-para-o-tratamento-da-covid-19/. Acesso em: 14 jun. 2020.

${ }^{15} \mathrm{Em}$ conclusão, o artigo aponta: "Conclusions and Relevance Among patients hospitalized in metropolitan New York with COVID-19, treatment with hydroxychloroquine, azithromycin, or both, compared with neither treatment, was not significantly associated with differences in in-hospital mortality. However, the interpretation of these findings may be limited by the observational design" (ROSENBERG, Eli S. et al. Association of treatment with hydroxychloroquine or azithromycin with in-hospital mortality in patients with Covid-19 in New York State. JAMA Network, maio 2020. Disponível em: https://jamanetwork.com/journals/jama/fullarticle/2766117. Acesso em: 14 jun. 2020).

${ }^{16}$ ASSOCIAÇÃO DE MEDICINA INTENSIVA BRASILEIRA (AMIB); SOCIEDADE BRASILEIRA DE INFECTOLOGIA (SBI); SOCIEDADE BRASILEIRA DE PNEUMOLOGIA E TISIOLOGIA (SBPT). Diretrizes para o tratamento farmacológico da Covid-19. 19 maio 2020. p. 3. Disponível em: https://www.amib.org.br/fileadmin/ user_upload/amib/2020/maio/19/Diretrizes_para_o_Tratamento_Farmacologico_da_COVID-19._Con senso_da_Associacao_de_Medicina_Intensiva_Brasileira__da_Sociedade_Brasileira_de_Infectologia_e_ da_Sociedade_Brasileira_de_Pneumologia_e_Tisiologia.pdf. Acesso em: 14 jun. 2020. 
No dia 21.5.2020, a Faculdade de Ciências Farmacêuticas da Universidade de São Paulo divulgou uma moção em face do mais recente protocolo do Ministério da Saúde, que indica a utilização do medicamento para o tratamento da Covid-19 até para os casos leves, afirmando, mais uma vez, a falta de estudos conclusivos que demonstrem a sua eficácia. O teor do documento corroborou aqueles divulgados pela Sociedade Brasileira de Imunologia, pela Organização Mundial da Saúde e por outros órgãos científicos de diversos países. ${ }^{17}$

A Organização Mundial de Saúde (OMS), em 25.5.2020, anunciou que o Grupo de Estudos Clínicos Internacional Solidariedade interromperia os testes com a cloroquina (e a hidroxicloroquina), em razão das preocupações com a segurança do medicamento. Nota divulgada em 3.6.2020 noticiou a retratação da OMS, que voltou a autorizar os testes com os referidos medicamentos para o tratamento da Covid-19. ${ }^{18}$ Em menos de quinze dias depois, no dia 17.6.2020, tornou a mudar a sua orientação e anunciou, mais uma vez, a suspensão dos testes. Justificou a decisão com a constatação científica de que esses medicamentos não têm reduzido a mortalidade em pacientes hospitalizados por Covid-19. No tocante aos pacientes que já haviam iniciado o tratamento com os tais remédios, dispôs que caberia ao médico, em conjunto com o próprio paciente, decidir sobre a manutenção do tratamento planejado. ${ }^{19}$

Voltando ao Brasil, em 25.6.2020, o Hospital Albert Einstein (São Paulo), que deixava a cargo do médico a decisão pela administração off label da cloroquina (e da hidroxicloroquina), passou a não recomendar o seu uso. Assim o fez, seguindo as recomendações da Administração de Alimentos e Drogas dos Estados Unidos (FDA), que revogou a autorização para a utilização emergencial da cloroquina no tratamento da Covid-19. ${ }^{20}$

Toda essa visão panorâmica é para apontar a franca divergência entre as orientações de agências e dos órgãos técnicos e científicos e o posicionamento do Governo Federal quanto ao uso do fármaco no tratamento do coronavírus. É

${ }^{17}$ FACULDADE DE CIÊNCIAS FARMACÊUTICAS (FCF). Moção da Faculdade de Ciências Farmacêuticas da Universidade de São Paulo sobre a ampliação do uso de cloroquina/hidroxicloroquina para casos leves de Covid-19. 21 maio 2020. Disponível em: http://info.fcf.usp.br/2020/?p=630. Acesso em: 14 jun. 2020.

18 ORGANIZAÇÃO MUNDIAL DE SAÚDE (OMS). Ensayo clínico "Solidaridad" sobre tratamientos contra la Covid-19. 3 jun. 2020. Disponível em: https://www.who.int/es/emergencies/diseases/novel-coronavirus-2019/globalresearch-on-novel-coronavirus-2019-ncov/solidarity-clinical-trial-for-covid-19-treatments. Acesso em: 14 jun. 2020.

${ }^{19}$ ORGANIZAÇÃO MUNDIAL DE SAÚDE (OMS). Ensayo clínico "Solidaridad" sobre tratamientos contra la Covid-19. 3 jun. 2020. Disponível em: https://www.who.int/es/emergencies/diseases/novel-coronavi rus-2019/global-research-on-novel-coronavirus-2019-ncov/solidarity-clinical-trial-for-covid-19-treatments. Acesso em: 14 jun. 2020.

${ }^{20}$ BATISTA, Everton Lopes. Einstein pede que médicos não prescrevam cloroquina a pacientes com Covid-19. Folha de S.Paulo, 26 jun. 2020. Disponível em: https://www1.folha.uol.com.br/equilibrioesaude/2020/06/ einstein-pede-que-medicos-nao-prescrevam-cloroquina-a-pacientes-com-covid-19.shtml. Acesso em: 2 jul. 2020. 
certo que, na ciência, não há verdades irrefutáveis e, em se tratando de uma doença nova, é possível observar-se a mudança de orientação a partir da evolução dos estudos científicos.

\section{A politização do uso off label da cloroquina e o ensejo ao vício de consentimento informado}

Na expectativa de uma rápida solução para evitar maiores danos à economia, o Governo Federal buscou amparo na alternativa que prometia cura mais imediata. Oxalá, estivesse certo e a cloroquina fosse efetivamente eficaz!

Logo no primeiro estágio da articulação de políticas públicas de combate ao coronavírus, em ato de resistência às medidas de isolamento social, determinado pela maioria dos estados federativos, veiculou a campanha "O Brasil não Pode Parar" nos canais oficiais do Governo, em oposição às unânimes orientações da Organização Mundial de Saúde, da comunidade científica nacional e internacional, do Conselho Federal de Medicina, da Sociedade Brasileira de Infectologia e, até mesmo, do próprio Ministério da Saúde, à época sob o comando do Ministro Luiz Henrique Mandetta.

Em face dessa campanha oficial, a Confederação Nacional dos Trabalhadores Metalúrgicos e o partido político Rede Sustentabilidade, com representação no Congresso Nacional, interpuseram arguições de descumprimento de preceito fundamental (ADPFs nos 668 e 669), fundamentadas nas ofensas ao art. 5으, XIV e XXXIII; art. 37, caput e §1ํ; art. 196 e art. 220, caput e $\S 1^{\circ}$ da Constituição Federal.

Decisão liminar do relator, Ministro Luís Roberto Barroso, determinou a vedação da circulação, em qualquer meio, de qualquer campanha que viesse a incentivar a população pelo retorno de suas atividades plenas quando os próprios Estados impunham medidas restritivas de circulação. Os processos foram extintos pela perda do objeto, quando as informações prestadas pela Presidência da República e pela Advocacia-Geral da União garantiram que a campanha seria encerrada. ${ }^{21}$

Sucederam-se as manifestações pró-bolsonaristas em frente ao Palácio do Planalto, contando com a presença do Presidente da República Jair Messias Bolsonaro, que não se poupou do contato físico com os seus apoiadores, em desatenção às determinações de distanciamento social. De outro lado, manifestações nas redes sociais propugnavam a necessidade do distanciamento.

\footnotetext{
${ }^{21}$ BRASIL. Supremo Tribunal Federal (STF). Liminar em ADPF 669. Min. Rel. Luís Roberto Barroso. Decisão monocrática. Brasília, DF, 31.3.2020. p. 1-20, publicada em 3.4.2020. Disponível em: http://portal.stf. jus.br/processos/downloadPeca.asp?id=15342798642\&ext=.pdf. Acesso em: 27 maio 2020.
} 
A postura do presidente da República acirrou as dificuldades para o enfrentamento da pandemia, a ponto de ensejar a sua denúncia ao Tribunal Penal Internacional de Haia (TPI) sob a acusação de crime contra a humanidade por omissão. A denúncia, promovida pelo Partido Democrático Trabalhista, reuniu diversos fatos, entre os quais aqueles que foram citados, com a finalidade de demonstrar que o comportamento presidencial tem prejudicado a contenção da expansão da doença. ${ }^{22}$

Com a saída do Ministro Nelson Teich, que ocupou o cargo por menos de um mês, a pasta da saúde segue sob a administração do interino, o Militar Eduardo Pazuello, que decidiu omitir, por determinação do presidente da República, os dados gerais de infectados e vitimados pelo coronavírus no país. Considerada a omissão atentatória ao dever de transparência e publicidade do Estado, arguições de descumprimento de preceito fundamental (ADPFs nำ 690, 691 e 692) foram ajuizadas pelos partidos políticos Rede Sustentabilidade, Partido Comunista do Brasil (PCdoB), Partido Socialismo e Liberdade (PSOL) e pelo Conselho Federal da Ordem dos Advogados do Brasil perante o STF. ${ }^{23}$

A pandemia acentuou a divergência política entre o Governo Federal e muitos governos estaduais e municipais, de sorte que não se logrou delinear uma política unificadora com diretrizes certeiras de enfrentamento à Covid-19. Mais uma vez, a matéria chegou à Corte Constitucional, por meio da Ação Direta de Inconstitucionalidade (ADI) no 6.341, interposta pelo Partido Democrático Trabalhista (PDT) em face da Medida Provisória no 926/2020. Coube ao Plenário do STF referendar a liminar deferida pelo Ministro Marco Aurélio, no sentido de que as medidas adotadas pelo Governo Federal, a partir da Medida Provisória (MP) no 926/2020, não poderão afastar a competência concorrente dos estados, Distrito Federal e municípios para o enfrentamento do coronavírus. ${ }^{24}$

Nesse caldeirão de acontecimentos e divergências, a cloroquina segue como medicação oficial a ser administrada para o tratamento do coronavírus (SARSCoV-2), acirrando-se a guerra entre os "cloroquiners" e "quarenteners". ${ }^{25}$

\footnotetext{
${ }^{22}$ Dados extraídos do portal do Partido Democrático Trabalhista (PDT) (MARQUES, Ester. Tribunal Penal Internacional atende pedido do PDT e analisa denúncia contra Bolsonaro. PDT 12, 8 jun. 2020. Disponível em: https://www.pdt.org.br/index.php/tribunal-penal-internacional-atende-pedido-do-pdt-e-analisa-denunciacontra-bolsonaro/. Acesso em: 13 jun. 2020).

${ }^{23}$ BRASIL. Supremo Tribunal Federal (STF). Medida Cautelar na ADPF 690. Min. Rel. Alexandre de Moraes. Brasília, DF, 8.6.2020, publicada em 12.6.2020. Disponível em: http://portal.stf.jus.br/processos/ downloadPeca.asp?id=15343377643\&ext=.pdf. Acesso em: 13 jun. 2020.

${ }^{24}$ BRASIL. Supremo Tribunal Federal (STF). Medida Liminar na ADI 6341. Min. Rel. Marco Aurélio. Plenário, Brasília, DF, 15.4.2020, publicada em 15.4.2020. Disponível em: https://portal.stf.jus.br/processos/ detalhe.asp?incidente=5880765. Acesso em: 2 jul. 2020.

25 TAVARES, Joelmir. Guerra entre 'cloroquiners' e 'quarenteners' reinventa polarização na pandemia. Folha de S.Paulo, 15 abr. 2020. Disponível em: https://www1.folha.uol.com.br/poder/2020/04/guerra-entrecloroquiners-e-quarenteners-reinventa-polarizacao-na-pandemia.shtml. Acesso em: 2 jul. 2020.
} 
Como já referido, o Ministério da Saúde, por meio da Nota Informativa no 5 , de 27.3.2020, ${ }^{26}$ recomendava a cloroquina (e a hidroxicloroquina) para os casos de pacientes hospitalizados em estado crítico. E, por meio de recomendação datada de 20.5.2020, passou a orientar ao SUS sobre a utilização desses medicamentos para o tratamento precoce da Covid-19. ${ }^{27}$ Mais recentemente, no mesmo dia em que o Hospital Albert Einstein de São Paulo se manifestou pela não recomendação dos medicamentos, como já referenciado no tópico anterior, o Ministério da Saúde ampliou o protocolo de utilização dessas drogas, autorizando o seu uso em gestantes e crianças. ${ }^{28}$

O Governo brasileiro não apenas adotou o uso da cloroquina (e da hidroxicloroquina) como política pública oficial, como passou a distribuir quites dos medicamentos para as pessoas que apresentam sintomas leves da doença, mediante a assinatura de um documento padrão, denominado Termo de Ciência e Consentimento para uso de Hidroxicloroquina/Cloroquina. ${ }^{29}$

A conduta presidencial em face do terror pandêmico e a sua insistência quanto ao uso da cloroquina repercutiu internacionalmente, e a revista médica The Lancet chegou a considerar o Presidente Jair Messias Bolsonaro "a maior ameaça à resposta do COVID-19 no país" ${ }^{30}$ Vê-se que, além dos riscos da prescrição off label do medicamento, que requer o consentimento informado do paciente, mal engendrado, há um forte apelo político do líder da nação orientando o seu uso.

Não se olvida da importância da voz do chefe político da nação. Pode influenciar ou induzir a população pela utilização de um remédio não recomendado cientificamente, e vir a comprometer o genuíno livre consentimento informado por parte do paciente. Em termos técnicos, o consentimento consiste no reconhecimento do paciente como um sujeito autônomo para decidir sobre utilização de uma medicação

${ }^{26}$ BRASIL. Ministério da Saúde. Nota Informativa no 5/2020-DAF/SCTIE/MS. Brasília, mar. 2020. Disponível em: http://www.cofen.gov.br/wp-content/uploads/2020/03/Nota-Informativa_05-2020_DAF_SCTIE_Cloroquina. pdf.pdf. Acesso em: 13 jun. 2020.

27 BRASIL. Ministério da Saúde. Orientações do Ministério da Saúde para manuseio medicamentoso precoce de pacientes com diagnóstico da Covid-19. Brasília, maio 2020. Disponível em: https://www.saude.gov.br/ images/pdf/2020/May/20/orientacoes-manuseio-medicamentoso-covid19.pdf. Acesso em: 13 jun. 2020.

28 BRASIL. Ministério da Saúde. Orientações do Ministério da Saúde para manuseio medicamentoso precoce de pacientes com diagnóstico da Covid-19. Brasília, jun. 2020. Disponível em: https://saude.gov.br/ images/pdf/2020/June/17/ORIENTA ES-D-PARA-MANUSEIO-MEDICAMENTOSO-PRECOCE-DE-PACIENTESCOM-DIAGN--STICO-DA-COVID-19.pdf. Acesso em: 3 jul. 2020.

${ }^{29}$ BRASIL. Ministério da Saúde. Anexo / - Modelo de termo de ciência e consentimento. Brasília, maio 2020. Disponível em: https://saude.gov.br/images/pdf/2020/May/20/Termo-de-Cie--ncia-e-ConsentimentoHidroxicloroquina-Cloroquina-COVID-19.pdf. Acesso em: 13 jun. 2020.

30 "Yet, perhaps the biggest threat to the country's COVID-19 response is its President, Jair Bolsonaro. [. ] When asked by Brazil as a country must come together to give a clear answer to the 'So what?' by its President. He needs to drastically change course or must be the next to go" (COVID-19 in Brazil: "So What". The Lancet, v. 395, maio 2020. p. 1461. Disponível em: https://www.abrasco.org.br/site/wp-content/ uploads/2020/05/09_05p1461ed.pdf. Acesso em: 15 jun. 2020). 
ou tratamento que lhe é indicado. A partir do respeito à sua integridade psicofísica e a sua autodeterminação, é que se consolida o direito ao consentimento e ao dissentimento acerca do tratamento que Ihe é proposto. Conclui-se que o paciente tem liberdade para decidir o que entende melhor para si. ${ }^{31}$

Brochado e Sá explicam que atitudes paternalistas que violam a autodeterminação do indivíduo são ilegítimas, porque atingem de forma imediata a dignidade da pessoa humana ${ }^{32}$ no corolário da autodeterminação. Partem da orientação proposta por Stefano Rodotà quanto à garantia de uma esfera pessoal indecibile per il legislatore, ou seja, o respeito a um espaço de escolha exclusiva do sujeito, como garantia ao exercício da liberdade existencial. ${ }^{33}$

Portanto, ainda que as normas não obriguem o paciente a usar referido fármaco, na forma off label, o discurso presidencial é bastante incentivador, mesmo sem as bases científicas que comprovem sua eficácia. O seu apelo tem importante influência na manifestação de vontade volitiva da população, podendo ensejar uma espécie de vício de consentimento. Até quando sintetiza, jocosamente: "Quem é de direita toma cloroquina. Quem é de esquerda toma Tubaína". ${ }^{34}$

Observem-se os deveres bioéticos associados ao processo de obtenção do consentimento do paciente. Há necessidade premente de fornecer uma informação clara e direta sobre as vicissitudes do tratamento. É indispensável considerar que "a capacidade dos pacientes de escolher, com efetiva liberdade, dependerá do quanto sabem sobre os prováveis benefícios e riscos do tratamento". ${ }^{35} \mathrm{Em}$ outros termos, é preciso entender que, além da função de preservação da autonomia, o consentimento informado possui as funções de informar e de "proteção dos pacientes e dos sujeitos de pesquisa contra danos e o encorajamento dos profissionais médicos para que ajam de forma responsável nas interações com pacientes e sujeitos de pesquisas". ${ }^{36}$

${ }^{31}$ ENGELHARDT JR., H. Tristram. Fundamentos da bioética. 4. ed. Tradução de José A. Ceschin. São Paulo: Loyola, 2011. p. 361.

32 TEIXEIRA, Ana Carolina Brochado; SÁ, Maria de Fátima Freire de. Cuidados paliativos: entre autonomia e solidariedade. Novos Estudos Jurídicos (Univali), v. 23, n. 1, p. 240-258, 1 quadr. 2018. p. 244. Disponível em: https://siaiap32.univali.br/seer/index.php/nej/article/view/13037. Acesso em: 13 jun. 2020.

${ }^{33}$ RODOTÀ, Stefano. Politici, liberateci dalla vostra coscienza. Ritagli, 5 jan. 2008. Disponível em: https://daleggere.wordpress.com/2008/01/13/stefano-rodota-\%C2\%ABpolitici-liberateci-dalla-vostracoscienza\%C2\%BB/. Acesso em: 13 jun. 2020.

${ }^{34}$ URIBE, Gustavo; CARVALHO, Daniel. Quem é de direita toma cloroquina. Quem é de esquerda toma Tubaína. Folha de S.Paulo, 19 maio 2020. Disponível em: https://www1.folha.uol.com.br/equilibrioesaude/2020/05/ bolsonaro-diz-que-novo-protocolo-sobre-cloroquina-sera-assinado-nesta-quarta-feira.shtml. Acesso em: 2 jul. 2020.

${ }^{35}$ ENGELHARDT JR., H. Tristram. Fundamentos da bioética. 4. ed. Tradução de José A. Ceschin. São Paulo: Loyola, 2011. p. 361.

${ }^{36}$ BEAUCHAMP, Tom L.; CHILDRESS, James F. Princípios de ética biomédica. 2. ed. Tradução de Luciana Pudenzi. São Paulo: Loyola, 2011. p. 162. 
Portanto, o termo de consentimento não pode se restringir à mera assinatura de um papel, sendo imprescindível a integração desse paciente no processo de tomada de decisão; trata-se de uma relação dinâmica baseada na boa-fé objetiva. Dessa forma, a assinatura do termo é apenas uma das exigências resultantes do processo, porque ao paciente precisa ser oferecida uma informação necessária e suficiente a partir de seu quadro clínico. ${ }^{37}$

Embora o ordenamento jurídico brasileiro não tenha uma legislação específica sobre o tema, Rosenvald e Braga Netto ${ }^{38}$ dispõem que o Código de Ética Médica (Resolução no 2.217/2018, DOU de 1‥11.2018) e as demais recomendações do Conselho Federal de Medicina (CFM) impõem aos profissionais o dever de atender às soluções regulamentares estabelecidas na legis artis, como é exemplo a Recomendação $\mathrm{n}$ - 1 de 2016 do CFM sobre o termo de consentimento livre e esclarecido. ${ }^{39}$

Diante das questões até aqui analisadas, revolve-se à questão primordial deste artigo: há responsabilidade civil da União pelos danos adversos causados às pessoas que receberem o tratamento com a cloroquina (ou a hidroxicloroquina) no período em que o fármaco figura no protocolo de atenção à doença no SUS? Especialmente, quando considerada a teoria do risco administrativo que fundamenta a responsabilidade civil do Estado, nos termos do art. 37, §6ㅇ da Constituição Federal. Secundariamente, questionam-se as implicações do discurso presidencial político pró-cloroquina nessa responsabilidade civil da União.

\section{Responsabilidade civil da União Federal pela politização da utilização off label da cloroquina para o tratamento da Covid-19}

No Brasil, a responsabilidade civil do Estado é fundamentada na teoria do risco administrativo (art. $37, \S 60$ da $\mathrm{CF} / 88)^{40}$ e aplica-se aos atos de império e

\footnotetext{
${ }^{37}$ ROSENVALD, Nelson; BRAGA NETTO, Felipe Peixoto. Responsabilidade civil na área médica. Revista Actualidad Jurídica Iberoamericana, v. 8, p. 373-420, fev. 2018. p. 414. Disponível em: http://idibe.org/ wp-content/uploads/2018/03/98. Rosenvald.pdf. Acesso em: 14 jun. 2020.

${ }^{38}$ ROSENVALD, Nelson; BRAGA NETTO, Felipe Peixoto. Responsabilidade civil na área médica. Revista Actualidad Jurídica Iberoamericana, v. 8, p. 373-420, fev. 2018. p. 475. Disponível em: http://idibe.org/ wp-content/uploads/2018/03/98.Rosenvald.pdf. Acesso em: 14 jun. 2020.

${ }^{39}$ CONSELHO FEDERAL DE MEDICINA. Recomendação CFM nำ1/2016. Dispõe sobre o processo de obtenção de consentimento livre e esclarecido na assistência médica. 21 jan. 2016. Disponível: https://portal. cfm.org.br/images/Recomendacoes/1_2016.pdf. Acesso em: 13 jun. 2020; CONSELHO FEDERAL DE MEDICINA. Resolução CFM nº 2.217/2018. Aprova o Código de Ética Médica. 1ำ nov. 2018. Edição 211. Seção 1. Disponível em: http://www.in.gov.br/materia/-/asset_publisher/Kujrw0TZC2Mb/content/ id/48226289/do1-2018-11-01-resolucao-n-2-217-de-27-de-setembro-de-2018-48226042. Acesso em: 13 jun. 2020.

40 CAVAlIERI FILHO, Sergio. Programa de responsabilidade civil. 11. ed. São Paulo: Atlas, 2014. p. 181.
} 
aos atos de gestão, seja por conduta comissiva seja omissiva do agente de quaisquer dos três poderes. Dessa forma, pelo princípio da responsabilidade objetiva do Estado, esse será responsável pelos danos que qualquer um de seus agentes causarem a terceiros. Até mesmo a conduta presidencial poderá suscitar a responsabilidade civil do Estado. Menezes e Serpa dispõem: "observa-se um alargamento constitucional do conceito de agente público para os fins da responsabilidade civil, sendo este assim considerado como aquele que age em nome do Estado". ${ }^{41}$

Destaque-se que é em razão da teoria do risco administrativo que a responsabilidade civil do Estado ocorre independentemente de culpa/dolo ou da prestação de bom ou mau serviço. É suficiente e igualmente imprescindível a prova do nexo causal entre o dano e a ação ou omissão do agente ou órgão público. ${ }^{42} \mathrm{As}$ hipóteses de excludente são admitidas e ocorrem pelo caso fortuito externo, haja vista a ruptura do nexo de causalidade entre o dano e a atividade do agente; pela força maior; pela culpa exclusiva da vítima e pelo fato de terceiro. ${ }^{43}$

Essa imposição do dever de indenizar do Estado independentemente de culpa eleva o Brasil a uma condição diferenciada no campo da responsabilidade civil, o que o diferencia de países como a França e a Itália, que não possuem um princípio geral de responsabilização estatal no texto constitucional, tratando a matéria apenas por dispositivos de leis. Entre nós, a constitucionalização da responsabilidade civil demonstra o caráter solidarista da Constituição Federal de 1988 que, também, ilumina o perfil funcional da responsabilidade civil em favor da vítima, tratando o direito à reparação como uma garantia fundamental. ${ }^{44}$

Corroboram Menezes, Lima e Costa quanto à tutela integral e efetiva da pessoa humana, exigindo que "a indenização possa albergar os instrumentos de efetiva promoção da pessoa humana, independentemente da fonte originária do

${ }^{41}$ MENEZES, Joyceane Bezerra de; SERPA, J. A. Responsabilidade civil da União pelos danos causados pela vacina contra a influenza - Síndrome Guillain-Barré (SGB). In: ROSENVALD, Nelson; MENEZES, Joyceane Bezerra de; DADALTO, Luciana (Coord.). Responsabilidade civil e medicina. Indaiatuba: Foco, 2020. p. 308.

${ }^{42}$ MENEZES, Joyceane Bezerra de; SERPA, J. A. Responsabilidade civil da União pelos danos causados pela vacina contra a influenza - Síndrome Guillain-Barré (SGB). In: ROSENVALD, Nelson; MENEZES, Joyceane Bezerra de; DADALTO, Luciana (Coord.). Responsabilidade civil e medicina. Indaiatuba: Foco, 2020. p. 308-309.

${ }^{43}$ MENEZES, Joyceane Bezerra de; SERPA, J. A. Responsabilidade civil da União pelos danos causados pela vacina contra a influenza - Síndrome Guillain-Barré (SGB). In: ROSENVALD, Nelson; MENEZES, Joyceane Bezerra de; DADALTO, Luciana (Coord.). Responsabilidade civil e medicina. Indaiatuba: Foco, 2020. p. 309.

44 "A teoria dos direitos fundamentais, a força normativa dos princípios (e sua aplicação direta às relações privadas), a funcionalização social dos conceitos e categorias, a priorização das situações existenciais em relação às patrimoniais, a repulsa ao abuso de direito, tudo isso ajuda a construir a teoria da responsabilidade civil do Estado no século XXI" (BRAGA NETTO, Felipe. Coronavírus e deveres estatais: o perfil dos novos tempos. In: MONTEIRO FILHO, Carlos Edison do Rêgo; ROSENVALD, Nelson; DENSA, Roberta (Org.). Coronavírus e responsabilidade civil: impactos contratuais e extracontratuais. Indaiatuba: Foco, 2020. p. 239). 
dever violado, seja no âmbito contratual ou extracontratual, de direito público ou privado". ${ }^{45}$

Atendida a situação da vítima, poderá o Estado exercer o direito de regresso em face do agente que, mediante conduta ilícita comprovada, contribuiu para a causa do dano. Quanto à apuração de ilícito cometido por agente público, enfocando-se neste momento pandêmico os profissionais da saúde que prestam serviço público, aplica-se a teoria da dupla garantia, por força da repercussão geral fixada pelo STF no julgamento do RE no 1.027.633/2017. Embora esses agentes possam ser responsabilizados civilmente pela forma subjetiva, não poderão ser acionados judicialmente pelo paciente que houver sofrido dano, porque a responsabilidade civil é dirigida ao Estado, objetivamente responsável. ${ }^{46} \mathrm{~A}$ consagração da dupla garantia ocorre para o cidadão que pleiteia responsabilidade civil diretamente em face do Estado e, por outro lado, ocorre para o agente que presta o serviço público, o qual não será acionado diretamente pelo cidadão, mas apenas pelo Estado na forma regressiva. Assim, no caso dos danos emergentes ocasionados pelo uso da cloroquina a partir da prescrição médica, o profissional da saúde não teria legitimidade processual passiva para responder em ação proposta pelo paciente.

Diante da extraordinária circunstância pandêmica, outro ponto merece destaque: a Medida Provisória (MP) no 966/2020, editada pelo Governo Federal em 13.5.2020, que tratou de restringir a responsabilidade civil e administrativa dos agentes públicos. Admitia-a somente nos casos de ação/omissão com dolo ou erro grosseiro, pela prática de atos relacionados, direta ou indiretamente, com as medidas de enfrentamento do coronavírus. Apreciada a constitucionalidade dessa medida em Ação Direta de Inconstitucionalidade (ADI) no 6.427, coube ao STF aplicar uma interpretação conforme a Constituição para o art. 2ํ da Medida Provisória no 966/2020 do Governo Federal. ${ }^{47}$ Considerou que o "erro grosseiro" deve ser compreendido como qualquer ato que viole o direito à vida, à saúde ou ao meio ambiente equilibrado, por desrespeito às normas e critérios técnicos e científicos. ${ }^{48}$

${ }^{45}$ MENEZES, Joyceane Bezerra de; LIMA, Martonio Mont'Alverne Barreto; COSTA, Adriano Pessoa da. Análise epistemológica da responsabilidade civil na contemporaneidade. Revista Brasileira de Direito Civil RBDCivil, Belo Horizonte, v. 21, p. 17-37, jul./set. 2019. p. 33.

${ }^{46}$ BRASIL. Supremo Tribunal Federal (STF). RE 1.027.633/2017. Min. Rel. Marco Aurélio. Brasília, DF, 14.8.2019. p. 1-30, publicada em 6.12.2019. Disponível em: http://portal.stf.jus.br/processos/down loadPeca. asp?id=15341907260\&ext=.pdf. Acesso em: 27 maio 2020.

${ }^{47}$ BRASIL. Governo Federal. Medida Provisória nº 966/2020. Dispõe sobre a responsabilização de agentes públicos por ação e omissão em atos relacionados com a pandemia da Covid-19. Brasília, DF, 13 maio 2020. Disponível em: http://www.planalto.gov.br/ccivil_03/_Ato2019-2022/2020/Mpv/mpv966.htm. Acesso em: 14 jun. 2020.

${ }^{48}$ BRASIL. Supremo Tribunal Federal (STF). Liminar em ADI 6421. Min. Rel. Luís Roberto Barroso. Brasília, DF, 21.5.2020, publicada em 3.6.2020. Disponível em: https://portal.stf.jus.br/processos/detalhe. asp?incidente=5912207. Acesso em: 14 maio 2020. 
Portanto, após essas breves ponderações, dois fatores chamam atenção para a responsabilização da União Federal no caso específico de enfrentamento da pandemia, pelos quais a teoria do risco administrativo seria suficiente para imputar a responsabilidade. O primeiro fator enseja a responsabilidade civil da União pelo simples fato de a adoção de política pública de utilização da cloroquina em caráter off labe/ contrariar o estado da arte da ciência, haja vista a farta literatura científica que demonstra a ineficácia do medicamento para o fim proposto e os elevados riscos que pode trazer para o usuário. Nesse caso, qualquer dano sofrido por efeito adverso associado ao medicamento suscitaria o dever de indenizar do Estado. O caráter geral e vinculativo do protocolo do Ministério da Saúde para o Sistema Único de Saúde (SUS), que ocorre por força da Lei no $8.080 / 90,{ }^{49}$ prejudica a individualização do tratamento para cada paciente, exigida para a licitude da prescrição off label, como explicado anteriormente.

Ainda, de forma mais grave, a Lei no 13.979/20 corrobora a qualificação da política pública já mencionada como inadequada ao estado da arte e, portanto, sujeita aos efeitos da responsabilização civil. A lei "dispõe sobre as medidas para enfrentamento da emergência de saúde pública de importância internacional decorrente do coronavírus responsável pelo surto de $2019 ",{ }^{50}$ estabelecendo que as medidas de combate à pandemia somente poderão ser determinadas com base em evidências científicas. Disso se conclui que a adoção, pelo Ministério da Saúde, de fármaco off label com grande controvérsia científica reforça a gravidade e a irresponsabilidade da política pública do Governo Federal, sobretudo se consideradas as orientações mais recentes da OMS (e de diversos outros órgãos e agências nacionais e internacionais) que determinaram a suspensão da utilização do medicamento.

O segundo fator que enseja a responsabilidade civil estatal é o discurso enfático presidencial em estimular uma falsa percepção da realidade acerca das propriedades de cura da cloroquina (e da hidroxicloroquina). Assim, a conotação política pela utilização do fármaco acaba nutrindo grande parte da população de falsas certezas pela cura, sem a compreensão dos concretos e potenciais riscos de danos pelos efeitos adversos. Nesse caso, estaria caracterizado o vício no consentimento informado do paciente.

\footnotetext{
${ }^{49}$ BRASIL. Lei $n^{\circ}$ 8.080/90, de 19 de setembro de 1990. Dispõe sobre as condições para a promoção, proteção e recuperação da saúde, a organização e o funcionamento dos serviços correspondentes e dá outras providências. Disponível em: http://www.planalto.gov.br/ccivil_03/leis//8080.htm. Acesso em: 14 jun. 2020.

${ }^{50}$ BRASIL. Lei no 13.979/20, de 06 de fevereiro de 2020. Dispõe sobre as medidas para enfrentamento da emergência de saúde pública de importância internacional decorrente do coronavírus responsável pelo surto de 2019. Disponível em: http://www.planalto.gov.br/ccivil_03/_ato2019-2022/2020/lei/L13979. htm. Acesso em: 14 jun. 2020.
} 
Isso porque não basta a garantia de uma autonomia existencial da pessoa em relação ao seu próprio corpo, assegurando-a de que se torne protagonista de si, pois no estado pandêmico vivenciado, em que as incertezas e cura chegam a gerar o desespero, a voz firme do chefe do Poder Executivo resulta na "falsa percepção" de que o medicamento é o melhor caminho a ser seguido, e isso, por si só, já relega a um papel secundário a informação prestada pelo médico, por mais esclarecedora que possa vir a ser.

Ademais, como explicam Valesi e Gozzo, "numa visão intrínseca do paciente, reconhece-se que ele possa se sentir mais vulnerável frente ao médico. Isto porque, por vezes, ele se sente aquém do poder-saber deste profissional", e continuam "a despeito das informações claras e compreensíveis que ele possa receber do médico, por vezes ele não se sente em condições de influenciar não só sobre as propostas de tratamento, mas, também, sobre a forma da condução de sua trajetória clínica". 51

Contudo, o fato aqui narrado vai além, e não se restringe apenas ao saber médico e o dever bioético de informar o paciente, pois, se o paciente se sente, muitas vezes, vulnerável ante o médico, vulnerável está, ainda mais, ante as reiteradas afirmações do presidente da República em indicar um fármaco já estigmatizado pela comunidade científica em geral, sobretudo quando essas afirmações são legitimadas pelo Ministério da Saúde.

Interessante, ainda, pontuar recente afirmação do então Ministro da Saúde Eduardo Pazuello, quando, em 18.1.2021, afirmou que a pasta ministerial não possui protocolo algum que oriente o uso da cloroquina/hidroxicloroquina para o tratamento da Covid-19, contrariando todas as evidências documentais advindas do Ministério da Saúde e consubstanciando verdadeiro descaso com a população. ${ }^{52}$ No mesmo dia em que Pazuello fez referidas negações, o presidente da República voltou a defender com insistência o que chama de tratamento precoce, estimulando, mais uma vez, o uso da cloroquina/hidroxicloroquina. ${ }^{53}$

${ }^{51}$ VALESI, Raquel; GOZZO, Débora. Medicação aplicável à Covid-19, consentimento do paciente e responsabilidade civil do médico. Revista lberc, Belo Horizonte, v. 3, n. 2, p. 241-267, maio/ago. 2020. p. 258. Disponível em: https://revistaiberc.responsabilidadecivil.org/iberc/article/view/130/96. Acesso em: 12 fev. 2021.

${ }^{52}$ COLETTA, Ricardo Della; CARVALHO, Daniel; LOPES, Raquel; CANCIAN, Natália. Documento contradiz Pazuello, que nega ter recomendado cloroquina. Folha de S.Paulo, 18 jan. 2021. Disponível em: https://www1.folha.uol.com.br/equilibrioesaude/2021/01/documento-contradiz-pazuello-que-nega-terrecomendado-cloroquina.shtml?origin=uol. Acesso em: 12 fev. 2021.

${ }^{53}$ CARVALHO, Daniel. Bolsonaro insiste em tratamento precoce e volta a lançar desconfiança sobre Coronavac. Folha de S.Paulo, 18 jan. 2021. Disponível em: https://www1.folha.uol.com.br/equilibrioesaude/2021/01/ bolsonaro-insiste-em-tratamento-precoce-e-volta-a-lancar-desconfianca-sobre-coronavac.shtml. Acesso em: 12 fev. 2021. 
Menezes e Serpa, ao estudarem sobre o dano injusto associado à vacina contra a gripe $\mathrm{H} 1 \mathrm{~N} 1$, potencialmente causadora da síndrome Guillain-Barré, explicaram que, diante do chamamento publicitário massivo do Governo para a imunização contra o vírus, fosse para o bem da saúde coletiva, fosse para a saúde individual do cidadão, deu-se um reforço da responsabilidade civil do Estado pelos efeitos adversos pós-vacinação. ${ }^{54} \mathrm{~A}$ partir de semelhante raciocínio, o discurso político e enfático do presidente da República, que chama a população para tomar cloroquina (e a hidroxicloroquina), seja para prevenir seja para tratar o coronavírus, mostra-se como uma verdadeira campanha que promete ilusoriamente uma solução para a pandemia. À revelia das orientações da comunidade científica, o discurso presidencial tem o potencial de ensejar um vício no consentimento dos usuários que passarão a usar o fármaco mesmo sem a segurança esperada.

Nesse caso, o termo de consentimento-padrão oferecido pelo SUS não consubstancia as exigências bioéticas de efetivação do consentimento informado a partir de uma relação holística entre médico e paciente. Isso porque essas exigências, em preservação à autonomia e dignidade humana do paciente, estabelecem que o consentimento não será válido apenas com a assinatura de um termo-padrão, mas com a efetivação de um verdadeiro diálogo participativo entre médico e paciente. Ademais, mesmo que essas informações venham a ser prestadas pelo médico, a própria vulnerabilidade das pessoas no momento pandêmico acaba depositando credibilidade na voz do chefe da nação, o que pode ter consequências irremediáveis.

\section{Conclusão}

A prescrição off label de medicamentos é lícita e, diante da situação desafiadora instaurada pelo coronavírus, quando os conhecimentos científicos sobre a doença são muito limitados, a alternativa é das únicas soluções possíveis. Especificamente no caso brasileiro, a utilização off label da cloroquina (e da hidroxicloroquina) passou a fazer parte das possibilidades farmacológicas administradas pelos médicos em tentativa de combater a doença. Mas a adoção off label desses fármacos ganhou contornos políticos a partir do apelo presidencial e ultrapassou a relação médico/paciente.

Após as subsequentes demissões dos ministros da saúde Luiz Henrique Mandetta e Nelson Teich, o Governo Federal, por meio do Ministério da Saúde,

${ }^{54}$ MENEZES, Joyceane Bezerra de; SERPA, J. A. Responsabilidade civil da União pelos danos causados pela vacina contra a influenza - Síndrome Guillain-Barré (SGB). In: ROSENVALD, Nelson; MENEZES, Joyceane Bezerra de; DADALTO, Luciana (Coord.). Responsabilidade civil e medicina. Indaiatuba: Foco, 2020. p. 322. 
adotou os fármacos no protocolo de tratamento da doença, inclusive, para os casos em que os sintomas são leves. Para ter acesso ao medicamento, basta que o paciente porte recomendação médica originária do Sistema Único de Saúde e assine o termo-padrão de consentimento.

Não obstante, a licitude da prescrição off label da cloroquina não abrange um uso indiscriminado e generalizado, mas requer o tratamento individualizado a seguir o quadro geral do paciente e o respeito à sua autodeterminação. Nesse contexto, considerando a discrepância entre a orientação do Ministério da Saúde e a comunidade médico-científica, os órgãos e agências nacionais e internacionais, sobretudo a OMS, que orientam pela não utilização do medicamento, qualquer efeito adverso danoso que a sua prescrição venha a causar ao paciente pode suscitar a responsabilidade civil da União.

Responsabilidade civil essa que se vê reforçada pelo discurso político do presidente da República que estimula o uso do tal fármaco para a cura do Covid-19. Trata-se de um discurso influenciador, que tem potencial para interferir na tomada de decisão do paciente, ensejando uma espécie de vício no consentimento.

Dessa forma, suspeita-se da validade de uma mera assinatura de um formulário nominado de termo de consentimento-padrão fornecido pelo Governo Federal. No plano do biodireito, o consentimento do paciente requer respeito a um processo consciente e informado para a tomada de decisões. Processo este no qual the seja permitido compreender a finalidade e as consequências daquela terapêutica.

Em face do exposto, e conforme a teoria do risco administrativo, é possível concluir que as situações apresentadas evocam a responsabilidade civil da União Federal por eventuais consequências danosas ao paciente usuário da cloroquina/ hidroxicloroquina, seja pelo fato de o Governo Federal estabelecer o seu uso na política pública que vincula o SUS em dissonância com o que dispõe o estado da arte, seja pelo estímulo presidencial ao uso do medicamento que potencialmente se apresenta como um fator que vicia a tomada de decisão pelo paciente.

Informação bibliográfica deste texto, conforme a NBR 6023:2018 da Associação Brasileira de Normas Técnicas (ABNT):

MENEZES, Joyceane Bezerra de; CÍRIACO, Patrícia K. de Deus. Responsabilidade civil da União Federal pela politização da utilização off label da cloroquina no tratamento da Covid-19. Revista Brasileira de Direito Civil - RBDCivil, Belo Horizonte, v. 29, p. 49-67, jul./set. 2021.

Recebido em: 04.07.2020

Aprovado em: 23.02.2021 